\title{
CONSUMO/CRÉDITO: UMA CONFIGURAÇÃO DESSA RELAÇÃO PELA PUBLICIDADE
}

\author{
Consumption/credit: a configuration of this relationship \\ through advertising \\ Consumo/crédito: una configuración de esta relación desde la \\ publicidad
}

\author{
Andréa Cristina de C. B. Corcione \\ Universidade de Sorocaba, Sorocaba, Brasil. \\ Mestre pelo Programa de Pós-Graduação em Comunicação e Cultura da Universidade de Sorocaba. \\ E-mail: andreacorcione@hotmail.com
}

\section{Maria Ogécia Drigo}

Universidade de Sorocaba, Sorocaba, Brasil.

Doutora em Comunicação e Semiótica pela Pontifícia Universidade Católica de São Paulo; pós-doutora pela Escola de Comunicação e Artes da Universidade de São Paulo e docente do Programa de Pós-Graduação em Comunicação e Cultura da Universidade de Sorocaba.

E-mail: maria.drigo@prof.uniso.br

RESUMO Com o objetivo averiguar como a relação consumo/crédito é engendrada pela publicidade, apresentam-se reflexões sobre consumo e crédito, sobre publicidade e análise de uma peça publicitária de 2010 da campanha "Não tem preço", para a MasterCard Brasil, aplicando estratégias advindas da semiótica peirciana. O cartão de crédito, ao propiciar o consumo de crédito, elimina o desejo de espera e, via publicidade, propicia a vivência de emoções e sentimentos ao propor sentidos e valores vinculados à família e ao futebol.

PALAVRAS-CHAVE Consumo, Crédito, Publicidade, Consumo de crédito.

ABSTRACT In order to verify how the consumption/credit relationship is engendered by advertising, we present reflections on consumption and credit; on advertising, and an analysis - from Peirce's semiotics - of one advertising piece of the 2010 Master Card Brazil campaign Não tem preço (It is priceless). The credit card, by providing the credit consumption, eliminates the waiting desire and, via advertising, provides the experiencing of emotions and feelings by proposing meanings and values related to family and football.

KEYWORDS Consumption, Credit, Advertising, Credit consumption.

RESUMEN Con el objetivo de investigar como la relación consumo/crédito se engendra en la publicidad, se presentan reflexiones sobre consumo y crédito, sobre publicidad y análisis de una pieza publicitaria en 2010 de la campaña "No tiene precio", para MasterCard Brasil, en la cual se aplican estrategias que vienen de la semiótica peirciana. La tarjeta de crédito, cuando propicia el consumo de crédito, elimina el deseo de espera y, vía publicidad, propicia también la vivencia de emociones y sentimientos cuando propone sentidos y valores vinculados a la familia y al futbol.

PALABRAS CLAVE Consumo, Crédito, Publicidad, Consumo de crédito. 


\section{INTRODUÇÃO}

Este artigo tem como tema o consumo e o crédito e objetiva explicitar o que se caracteriza como consumo de crédito, bem como averiguar como a publicidade pode contribuir para propagar valores relacionados a tal modalidade de consumo. Para alcançar tais objetivos, tratamos de aspectos do consumo e do crédito, na perspectiva de Bauman (1998; 2010) e realizamos a análise semiótica de uma peça publicitária da campanha "Não tem preço", para o Cartão MasterCard. A análise utiliza estratégias metodológicas advindas da gramática especulativa, um dos ramos da semiótica ou lógica desenvolvida por Charles Sanders Peirce, propostas por Santaella (2005).

As peças publicitárias são vistas como signos, por provocar efeitos nos possíveis intérpretes, tanto pelos seus aspectos qualitativos como pelos referenciais ou convencionais. Os aspectos qualitativos estão presentes nas cores, formas, texturas, no movimento ou nos jogos estabelecidos com tais elementos que fluem pelas imagens; os referenciais são as pistas latentes na imagem e que reportam o intérprete a coisas existentes, enquanto os aspectos convencionais, as regras ou as normas compartilhadas em uma cultura, estão impregnados nos aspectos qualitativos e referenciais.

Um signo “'representa' algo para a ideia que provoca ou modifica. [Ou seja], é um veículo que comunica à mente algo do exterior. O 'representado' é o seu objeto; o comunicado, a significação, a ideia que provoca, o seu interpretante” (PEIRCE, 1974, p. 99). Na análise, consideram-se fundamentos do signo os aspectos que capacitam qualquer objeto a ser signo: os qualitativos, os referenciais e os aspectos compartilhados culturalmente.

Conforme Santaella (2005), o primeiro olhar que devemos dirigir ao signo para análise de seus sistemas concretos é o contemplativo, que capta os aspectos qualitativos; o segundo, observacional, apanha as pistas, os aspectos referenciais, enquanto o terceiro tipo de olhar é aquele capaz de abstrair o geral do particular, extrair de um dado fenômeno aquilo que ele guarda em comum com todos os outros com que compõem uma classe geral. Com esses três tipos de olhar, pretendemos encontrar os valores que a publicidade propõe, com o consumo de crédito, para a peça publicitária selecionada da campanha "Não tem preço", da MasterCard.

Iniciamos com reflexões sobre consumo e crédito.

\section{SOBRE CONSUMO E CRÉDITO}

Para Bauman (1998, p. 88), vivemos em uma sociedade em que seus membros são moldados para exercer o papel de consumidor: "A norma que nossa sociedade coloca para seus membros é a da capacidade e vontade de desempenhar esse papel”. A sociedade moderna, na sua fase industrial, era uma sociedade de produtores e também de consumidores, assim como todas as pessoas consomem desde tempos imemoriais. No entanto, no atual estágio pós-moderno, sem tanta necessidade de mãode-obra industrial em massa e de exércitos recrutados, preconiza-se que a vida não pode ser vivida de outra forma, que não a de ser consumidor. No entanto, essa maneira de viver é disfarçada, ou seja, mostra-se para os consumidores como um livre exercício da vontade. "Eles são os juízes, os críticos e os que escolhem” (Ibidem, p. 92). Os consumidores são, portanto, acumuladores de sensações e colecionadores de coisas e trocam "um bocado de segurança pela crescente remoção de restrições que tolhem o exercício da livre escolha, que gera os sentimentos amplamente difundidos de medo e ansiedade” (Ibidem, p. 92). 
Nos moldes atuais e como compressora do tempo, a tecnologia requer que tudo seja "agora”, ou seja, impõe dificuldades para a sociedade, pois o consumo demanda tempo. Isso constitui preocupação para os que negociam os bens de consumo. Nas palavras de Bauman (1998, p. 90):

No que diz respeito a esta lógica, a satisfação do consumidor deveria ser instantânea e isso no duplo sentido. Obviamente, os bens consumidos deveriam satisfazer de imediato, sem exigir o aprendizado de quaisquer habilidades ou extensos fundamentos; mas a satisfação deveria também terminar - "num abrir e fechar de olhos", isto é, no momento em que o tempo necessário para o consumo tivesse terminado.

Assim, fazer com que os consumidores não possam prestar atenção ou concentrar o desejo por muito tempo em qualquer objeto ou coisa desejada é uma das estratégias. Com isto, eles passam a ser "impacientes, impiedosos, indóceis e, acima de tudo, facilmente instigáveis”, bem como potencialmente capazes de perder o interesse facilmente. Desse modo, "a espera é retirada do querer e o querer da espera, a capacidade do consumo dos consumidores pode ser esticada muito além dos limites estabelecidos por quaisquer necessidades naturais ou adquiridas; também a durabilidade física dos objetos não é mais exigida” (Ibidem, p. 90). 0 cartão de crédito também é uma estratégia com potencial, segundo o mesmo autor, para eliminar o desejo da espera.

Os consumidores, para Bauman (1998, p. 91), "precisam ser mantidos acordados e em alerta sempre, continuamente expostos a novas tentações, num estado de excitação incessante - e também, com efeito, em estado de perpétua suspeita e pronta insatisfação”. Esse movimento não traduz malestar, mas promessa de bem-aventurança. O capitalismo, de acordo com 0 mesmo autor, é um sistema parasitário que prejudica seu hospedeiro, pois a função da oferta é criar mais demanda. Assim, se é fundamental evitar que as necessidades sejam satisfeitas, então os empréstimos também devem criar a necessidade de novos empréstimos. O cartão de crédito, como uma carta que possibilita a entrada no jogo - que livra a pessoa da exclusão - deve contribuir para a permanente necessidade de crédito, ou seja, para o consumo do crédito.

Conforme Bauman (2010, p. 28), "nos velhos tempos, felizmente passados e esquecidos, era preciso adiar a satisfação”. Este princípio, que tornou possível o advento do capitalismo moderno, como explica o autor, levou as pessoas a economizar, a abrir mão de alegrias e gastar com parcimônia. A caderneta de poupança tornou-se a possibilidade (real) de transformar sonhos em realidade.

Atualmente, não é mais necessário adiar a realização de desejos, pois os bancos asseguram que desejar algo e não ganhar o suficiente para adquiri-lo não é mais um problema. Os cartões de crédito, conforme Bauman (2010, p. 28), foram lançados há cerca de trinta anos, com o slogan: "Não adie a realização dos seus desejos”. Com eles veio, portanto, a promessa de administrar a satisfação das pessoas, dando-lhes as coisas assim que elas as desejassem.

No entanto, os cartões (os empréstimos) devem ser pagos. Não pensar no futuro, acumula problemas, uma vez que o pagamento dos cartões envolve juros. A pressa da satisfação transforma-se, portanto, para o consumidor, em punição. $O$ “desfrute agora, pague depois”, para os bancos, tornou-se numa fonte de lucro. Os credores não têm pressa em reaver o dinheiro, pois oferecem mais crédito para pagar a velha dívida, que se transforma 
numa nova dívida e assim sucessivamente. Os bancos credores, com os juros cobrados mensalmente, encontraram uma nova fonte de lucros. Os clientes que pagam seus empréstimos, ou que se recusam a gastar o que ainda não ganharam, são como um pesadelo, não têm utilidade alguma.

Para garantir seu lucro, assim como o de seus acionistas, bancos e empresas de cartão de crédito contam mais com o "serviço" continuado das dívidas do que com seu pronto pagamento. Para eles, o "devedor ideal" é aquele que jamais paga integralmente suas dívidas. Os indivíduos que têm uma caderneta de poupança e nenhum cartão de crédito são vistos como um desafio para as artes do marketing: "terras virgens", clamados pela exploração lucrativa. Uma vez cultivadas (ou seja, incluídas no jogo dos empréstimos), não pode mais permitir que escapem, que entrem "em repouso". Quem quiser quitar inteiramente seus débitos antes do prazo deve pagar pesados encargos. (BAUMAN, 2010, p. 30)

O objetivo dos bancos e empresas de cartão de crédito, para o mesmo autor, é constituir devedores e perpetuar a condição de endividado. Emprestar dinheiro cria dependência, talvez maior que de outras drogas, e a única possibilidade para se desintoxicar é chegar às raízes do problema. Contudo, nada foi feito pelas instituições financeiras e pelo Estado para tanto. As medidas do governo buscam recapitalizar os bancos, para deixá-los desenvolver suas atividades normais, principal responsável pela crise atual, que parece não ter solução tão imediatamente.

Mas, vejamos como a publicidade se interpõe entre o consumo e o crédito. Para tanto, tratamos da publicidade, considerando-se ideias de Rocha (1995) e Lipovetsky (2007) e, em seguida, realizamos análise semiótica de uma peça publicitária que tem como tema o consumo, via cartão de crédito.

\section{A PUBLICIDADE E O CONSUMO DE CRÉDITO}

Rocha (1995) considera que a publicidade é um instrumento que permite resgatar o humano ao produto industrial, que no seu processo de produção afastou-se dele, situando-o na sua última plataforma - uma espécie de altar de sacrifício, onde será finalmente imolado e destruído na vertigem do consumo. O consumo se dá no circuito das trocas sociais que são essencialmente simbólicas.

A publicidade, para o autor, constrói significados para os bens de consumo ao reproduzir ou revelar nossos valores e crenças. Sendo assim, a curiosidade e o fascínio pela publicidade tendem a crescer. 0 mundo que a publicidade constrói é parecido com a vida: "no entanto, completamente diferente, posto que sempre bem-sucedido. Onde o cotidiano se forma em pequenos quadros de felicidade absoluta e impossível. Onde não habitam a dor, a miséria, a angústia, a questão” (Ibidem, 1995, p. 25).

O mundo idealizado, mágico, de equilíbrio e de bem-estar é construído pela publicidade com representações que propiciam a vivencia de sensações, emoções, que atingem a sociedade como um todo, transformando hábitos e, provavelmente, aumentando o consumo. Se não aumenta o consumo, de modo geral, ao menos aumenta o consumo da própria publicidade, uma vez que esta propaga estilos de vida e relações humanas; enquanto o produto vende somente para quem pode comprá-lo.

Ao projetar um estilo de vida, a publicidade insere o produto no cotidiano das pessoas, de outra forma, para além da sua existência enquanto tal. Dessa forma, realiza a mágica de incluir os produtos nas relações sociais. Ela narra feitos mágicos valendo-se de palavras, cores, movimentos, imagens 
e outros recursos. Lá, nesse mito, nesse sonho, nesse conto de fadas não há solidão, doença ou opressão. Tudo flui. Tudo se resolve. Muitos anúncios são construídos com essa moldura, ou seja, apresenta-se um problema e sua solução. "Assim os anúncios podem ser tomados como mitos, como narrativas de modelos ideais do cotidiano” (Ibidem, p. 140).

Nosso cotidiano é invadido por informação publicitária, nas mais diferentes mídias. A publicidade, na perspectiva desse mesmo autor, é como o visto de saída da produção e o visto de entrada no consumo, mas, como existem diferentes objetos, as imagens traduzem impressões diversas, que podem ser conservadoras ou avançadas, na moda ou clássica, austera ou arrojada. Ao diferenciar, caracterizar e identificar um produto, a publicidade propõe especificidades relativas a sexo, idade, estilo de vida, trajetória pessoal e poder aquisitivo. Logo, segundo Rocha (1995), ela constrói mapas de orientação social que são captados pelos consumidores, independentemente da venda efetiva do produto. Os processos de recepção não podem ser evitados, como receptores vivemos em meio à publicidade.

A possibilidade de existência de uma vida paralela, como menciona Rocha, pode ser contestada. A publicidade, ao exibir valores e crenças que permeiam a sociedade, em certa medida, agregam significados aos bens de consumo, fazendo com que estes incorporem uma natureza sígnica. Assim, considerando-se que os objetos e os signos não estão em mundos separados, a existência de tal vida paralela se inviabiliza.

Nesse contexto, a publicidade adota uma nova roupagem e também uma nova maneira de fazer parte da vida das pessoas, sem dúvida. A nova roupagem está vinculada à força das imagens que consolidam grandes marcas, ou marcas-estrela planetárias. Lipovetsky (2007) explica que as campanhas publicitárias se distanciam da valorização repetitiva do produto, dando preferência ao espetacular, ao lúdico, ao humor, à surpresa e à sedução dos consumidores. A ideia de vender um produto, um modo de vida, um imaginário, ou valores que provoquem algum tipo de emoção, não é mais o foco das campanhas. As intenções da persuasão comercial já não são mais as mesmas; não basta inspirar confiança, fazer conhecer e memorizar um produto. A publicidade deve ser "espetacular e deslocada, onírica e cúmplice” (Ibidem, p. 96), ou seja, ela deve construir um jogo com o consumidor e alinhar-se "pelos princípios da moda (mudança, fantasia, sedução), que está em sintonia com o comprador emocional e reflexivo" (Ibidem, p. 96-97) do consumo atual.

Para o autor, a publicidade não cria um estilo de existência radicalmente novo, mas procura estabelecer uma relação de cumplicidade, jogar com o público, fazê-lo compartilhar um sistema, criar uma proximidade emocional.

Assim, o modelo clássico da publicidade, o copy strategy, cujo propósito era fixar uma mensagem na mente do consumidor e que, em geral, enfatizava os benefícios funcionais ou psicológicos de determinado produto já é inadequado. Tal modelo tinha como pressuposto um sujeito passivo, que daria a resposta esperada e conhecida pelo produtor da mensagem, ou seja, o consumidor era condicionado pela repetição de slogans simples e breves. Esse modelo não foi totalmente abolido e a lógica engendrada nesse modelo, se encontra agora em concorrência com novas possibilidades, que levam em conta o aparecimento de um consumidor educado para o consumo.

Nesse aspecto, a publicidade se libertou, portanto, da racionalidade argumentativa. Agora, enquanto criativa, ela se insere no território do imaginário puro, livre da verossimilhança, aberto à criatividade sem 
barreiras. Desse modo, o consumidor não é enganado pela publicidade, mas encantado.

A publicidade está em alta, segundo Lipovetsky (2007), pois ela difunde valores e mensagens de sentido. Ela exalta o que é consenso, sem exercer o controle da cultura pelo poder da marca, ou seja, a publicidade, agora, "aparece mais como uma caixa de ressonância que como um agente de transformação social e cultural. Ela educava o consumidor, agora 0 reflete" (Ibidem, p.182).

Entre as concepções de publicidade, seguindo Lipovetsky (2007), consideramos que essa mídia é como uma "caixa de ressonância" que, metaforicamente, traduz o potencial de aumentar a duração ou a intensidade de sentidos e valores engendrados pela publicidade, quando buscam ser espetaculares, oníricas e cúmplices do consumidor/intérprete.

Para explicitar como a publicidade pode engendrar tais aspectos, aplicamos estratégias semióticas de análise, em uma das peças publicitárias da campanha "Não tem preço", da MasterCard.

"FINALMENTE COMPLETAR SEU ÁLBUM... NÃO TEM PREÇO”

A campanha da MasterCard criada pela McCann-Erickson iniciou-se em 2005, seguindo o conceito criativo "Não tem preço". Entre as peças dessa campanha, selecionamos a denominada "Figurinha", veiculada em 2010.

Nos recortes realizados - partes que compõem a peça veiculada na TV e selecionada no YouTube - predominam os tons amarelo e verde, como pode se observar no painel composto com seis cenas da peça (Figura 1).
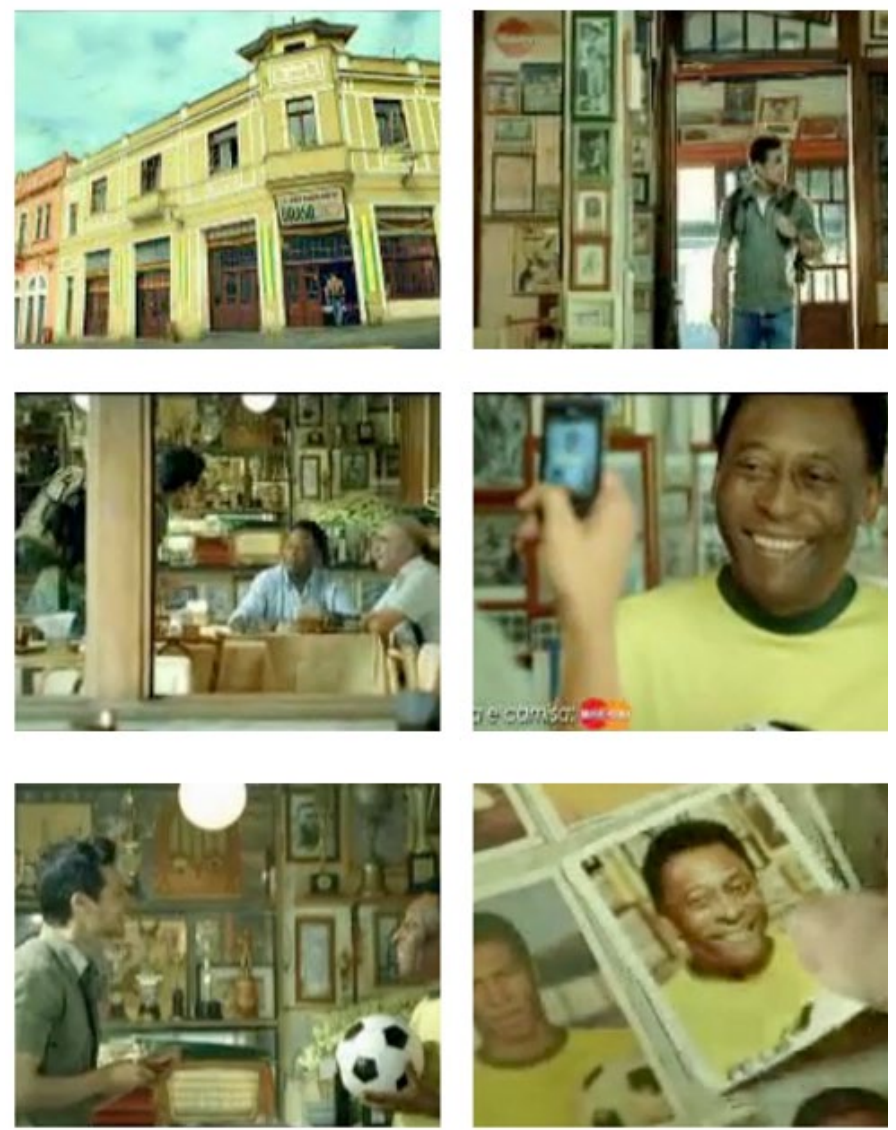

Figura 1. A peça "Figurinha" em seis recortes.

Fonte: Imagens elaboradas a partir da peça publicitária "Figurinha". Disponível em: <https://goo.gl/Sp1GkE>. Acesso em: 10 fev. 2014. 
Conforme Farina (1990), a cor produz sensação de movimento, de expansão e de reflexão. No caso, o amarelo pode ser associado afetivamente ao conforto, à espontaneidade e à euforia, enquanto o verde, afetivamente, se vincula à serenidade, ao bem-estar, à tranquilidade. As cores mencionadas, não saturadas, sugerem expansividade tímida e serena. O som - suave e lento - que acompanha as imagens amarelo-esverdeadas contribuem para realçar laços de amizade, de amor e de admiração. $O$ intérprete pode se envolver com tais aspectos qualitativos e os efeitos gerados podem estar vinculados à atmosfera de serenidade e afetividade.

Mas, um intérprete pode observar e simplesmente identificar a peça publicitária. A presença do rei do futebol, Pelé, reforça esse aspecto. No entanto, há outros aspectos referenciais que intensificam os vinculados aos qualitativos mencionados e, sendo assim, a peça publicitária pode gerar, predominantemente, efeitos emocionais. As cenas iniciais mostram o restaurante instalado em um casarão, em um bairro antigo, que em meio a tons amarelados exibe, no seu interior, muitos retratos e um mobiliário clássico, com muita madeira. Esse material pode ser associado afetivamente à sabedoria que vem das simbologias de bosques sagrados. Entre povos antigos, como os romanos, por exemplo, o bosque sagrado ou a floresta, segundo Chevalier e Gheerbrant (2008, p. 580), “é um centro de vida, uma reserva de frescor, de água e calor associados, como uma espécie de útero”.

Assim, o aspecto antigo e a madeira presentes no local sugerem requinte e aconchego, enquanto a grande quantidade de retratos valoriza a memória das pessoas, de um lugar, de um país. A peça pode propiciar efeitos emocionais que podem também estar relacionados ao passado e, mais especificamente, à trajetória do Brasil nos campeonatos mundiais de futebol (ver Figura 1).

Barthes (2006) enfatiza que toda a sutileza da fotografia está na certeza de que ela fala daquilo que foi, de um instante capturado no passado. Diante de uma foto, a consciência não toma necessariamente a via nostálgica da lembrança se as fotografias estão fora do tempo individual, mas a via da certeza. Assim, a essência da fotografia consiste em ratificar o que ela representa.

As fotos que cobrem parte das paredes do restaurante - retratos de jogadores dos campeonatos mundias de futebol - constroem uma atmosfera que reaviva a identidade nacional, no caso, o afeto que leva 0 intérprete (ou espectador) a se interessar pela fotografia, o studium, nos dizeres de Barthes (2006).

Assim, a grande quantidade de retratos instaura uma atmosfera que incita o intérprete a reavivar as suas experiências com os campeonatos mundiais dos quais o Brasil participou (e venceu, principalmente), trazendo à tona emoções e sentimentos vinculados à identidade nacional, ou resquícios desta identidade, que se firmou também com o futebol.

Vejamos os aspectos compartilhados culturalmente e que provocam novos efeitos no intérprete. Os tons verdes e amarelos, por sua vez, trazem à tona a bandeira brasileira (Figura 1), símbolo nacional, o que reforça os efeitos mencionados. Com a globalização, de modo geral as bandeiras passam a ser vistas como logomarcas, ou seja, se transformaram em logomarcas de consumo ou de uma forma de consumo. As bandeiras aparecem estampadas em camisetas, jaquetas, calças e em outros produtos que circulam em diferentes países. Segundo Orlandi (2002), o discurso no contexto pós-moderno tem necessidade de afirmar uma identidade. Com a peça - neste caso, com a presença da 
bandeira -, o intérprete pode considerar que se afirma ou se (re)afirma a identidade nacional brasileira. A bandeira é símbolo de proteção e, conforme Chevalier e Gheerbrant (2008, p. 119), a esse símbolo "acrescenta-se o valor do signo distintivo: bandeira de um senhor feudal, de um general, de um chefe de Estado, de um santo, de uma pátria etc.”.

A peça conjuga imagens e sons e é finalizada com a expressão: "Finalmente completar seu álbum... não tem preço". Assim, em relação à produção, essa peça tem o diferencial de valer-se de recursos distintos da palavra. Não há predominância de um discurso persuasivo empreendido com o uso de palavras, mas um jogo com aspectos qualitativos - cor, forma, texturas, movimento, bem como aspectos indiciais e simbólicos que levam o intérprete a associá-los a afetos, emoções.

A cena final é permeada por um monólogo, com a voz off que afirma "não tem preço”. Esse discurso demonstra autoridade, poder e domínio. Quanto à modalidade, o discurso autoritário pode ser analisado em função de quatro elementos: distância, modalização, tensão e transparência. No elemento distância, o sujeito falante é exclusivo; na modalização há o uso do imperativo; na modalidade tensão há imposições à fala entre emissor e receptor; e, por fim, na modalidade transparência, o discurso deve ser compreendido de forma rápida e direta. Pelé, nessa peça, em meio a um discurso autoritário e transparente, traduz o apelo à autoridade, a fim de validar a afirmação: "Finalmente, completar seu álbum... não tem preço".

Consideramos que a marca - no caso, a MasterCard - propõe o uso de cartões ou o consumo de crédito para "pagar" algo que não tem preço, ou seja, algo cujo valor não pode ser estimado em moeda corrente. Os laços afetivos entre pai e filho são reforçados com o auxílio da marca. Vale lembrar que a tendência de retomar os valores vinculados à família pode ser atribuída, de um lado, às transferências de funções, antes do Estado, para a comunidade e para a família, o que é favorecido pelo modelo neoliberal. De outro, à falência do estado de bem-estar social que, conforme Bauman (1998, p. 51), foi concebido como uma estratégia, na qual "os dispositivos da previdência eram então considerados uma rede de segurança, estendida pela comunidade como um todo, sobre cada um dos seus membros - a todos fornecendo a coragem para enfrentar o desafio da vida”. Desse modo, diante da "piora das condições de vida e [da] deterioração progressiva de um Estado teoricamente protetor das classes populares, haveria um ressurgimento da família” (GOLDANI, 1994, p. 304).

Nesse sentido, tal modalidade de consumo propicia compensações que estão muito além do que o consumo de bens materiais pode propiciar. Essa modalidade de transação tem o consentimento de Pelé e pode trazer para a vida das pessoas (dos consumidores) todas as emoções e sentimentos atrelados ao pertencimento à nação brasileira e, de modo especial, reverencia o futebol, que arrebata todos os brasileiros. Vale ressaltar que no início do século XIX o futebol já havia se tornado o esporte nacional, pois, segundo Rosenfeld (2013, p. 88), “como espetáculo envolvia todos os círculos masculinos, inclusive as elites, as quais, nos grandes encontros futebolísitcos, se irmanavam às massas em euforia festiva, na circunferência reboante do estádio".

Vejamos os sentidos que a música pode agregar à marca e ao consumo de crédito. Os instrumentos utilizados levam o usuário/intérprete - caso o seu repertório inclua conhecimentos sobre música - a identificar um sintetizador fazendo o som de teclado e uma viola caipira. Fica muito claro que as relações apresentadas fundem-se: Pelé, primeiro do mundo; 
futebol, paixão nacional; viola caipira, tradição brasileira; família, bem que não tem preço; e MasterCard para todas as outras coisas.

Os sentidos que a peça engendra, portanto, vêm da mistura de linguagens. A linguagem visual, a sonora e a verbal mesclam-se construindo uma ambiência em que o desejo se intensifica e se satisfaz rapidamente. No entanto, o tecido qualitativo construído, permeado pelos valores dos laços familiares trazidos à tona, bem como os relativos ao futebol enquanto símbolo da identidade nacional, pode contribuir para que o consumo de crédito, com o MasterCard, continue a reavivar e a realizar desejos.

\section{CONSIDERAÇÕES FINAIS}

Se somos moldados para o consumo, conforme enfatiza Bauman, então esse movimento instaura-se com uma ambiência permeada de valores atrelados às relações familiares e também ao futebol, enquanto componente da identidade nacional, no caso do envolvimento do intérprete com a peça analisada. Independentemente do fato de o intérprete vir a consumir crédito com o uso do cartão - entre as inúmeras experiências de interpretação, pois a peça insiste e persiste diante do intérprete por caminhar incessantemente por diversas mídias, e a mudança de hábito: 0 uso do cartão para realizar compras - há uma distância, um silêncio, um intervalo aberto para a contemplação, a ação e a reflexão.

Esse intervalo não constitui um universo paralelo, tal como menciona Rocha (1995). Ele está inserido no mesmo universo - o das coisas e dos efeitos que elas provocam, ou das relações que constrõem com seus usuários, ou dos signos e dos seus efeitos. Sem contar que esse intervalo comporta também o resultado de experiências continuadas com o ato de compra, o ato de comprar com cartões, o hábito de não consumir, as experiências no âmbito familiar, ou as experiências com o futebol. Os possíveis interpretantes, ou os possíveis efeitos da peça publicitária, enquanto signo, elencados no processo interpretativo, vieram não só dos aspectos simbólicos que ela engendra, mas também dos qualitativos e referenciais. Os aspectos qualitativos podem levar o intérpete à contemplação, ou seja, provocam efeitos emocionais; os referenciais permitem a identificação, o reconhecimento do objeto; os aspectos símbólicos, por sua vez, inserem o intérprete na cultura que ele compartilha. Os aspectos simbólicos, nessa interpretação, retomam a experiência, o cotidiano, os aspectos sensoriais. São esses efeitos, colocados em cheque com sua experiência de vida, que permitem ao intérprete levar adiante suas escolhas.

O intérprete, portanto, inserido no mundo das coisas e dos signos que não são estanques-, coloca-se então, com a interpetação, como um sujeito emancipado, capaz de avaliar o quanto as marcas, via publicidade, o reflete, sendo espetacular, onírica ou mesmo sua cúmplice. Ele sabe jogar ou situar-se no movimento das coisas e dos signos.

\section{REFERÊNCIAS}

BARTHES, R. A câmara clara. Lisboa: Edições 70, 2006

BAUMAN, Z. O mal-estar da pós-modernidade. Rio de Janeiro: Zahar, 1998. Vida a crédito. Rio de Janeiro: Zahar, 2010.

CHEVALIER, J.; GHEERBRANT, A. Dicionário de simbolos: mitos, sonhos, costumes, gestos, formas, figuras, cores, números. Rio de Janeiro: José Olympio, 2008.

FARINA, M. A psicodinâmica das cores em comunicação. São Paulo: Blucher, 1990. 
GOLDANI, A. M. Retratos de família em tempos de crise. Revista Estudos Feministas,

Florianópolis, v. 2, p. 302-335, 1994.

LIPOVETSKY, G. A felicidade paradoxal: ensaio sobre a sociedade de hiperconsumo. São Paulo: Companhia das Letras, 2007.

ORLANDI, E. Língua e conhecimento linguístico: para uma história das ideias no Brasil. São Paulo: Cortez, 2002.

PEIRCE, C. S. Escritos coligidos. São Paulo: Abril Cultural, 1974. v. XXXVI. (Coleção Os Pensadores).

ROCHA, E. P. G. Magia e capitalismo: um estudo antropológico da publicidade. São Paulo: Brasiliense, 1995.

ROSENFELD, A. Negro, macumba e futebol. São Paulo: Perspectiva, 2013.

SANTAELLA, L. Matrizes da linguagem e pensamento. São Paulo: Iluminuras, 2005. 